\title{
Addressing the variation in hepatic surgery for colorectal liver metastasis
}

\author{
Rachel V. Guest ${ }^{1}$, Kjetil Søreide ${ }^{2,3}$ \\ ${ }^{1}$ Department of Clinical Surgery, University of Edinburgh, Little France Crescent, Edinburgh, UK; ${ }^{2}$ Department of Gastrointestinal Surgery, HPB \\ Unit, Stavanger University Hospital, Stavanger, Norway; ${ }^{3}$ Department of Clinical Medicine, University of Bergen, Bergen, Norway \\ Correspondence to: Prof. Kjetil Søreide, MD PhD FRCS FACS. Department of Gastrointestinal Surgery, HPB Unit, Stavanger University Hospital, \\ Stavanger, Norway. Email: ksoreide@mac.com. \\ Comment on: Fenton HM, Taylor JC, Lodge JPA, et al. Variation in the Use of Resection for Colorectal Cancer Liver Metastases. Ann Surg \\ 2019;270:892-8.
}

Submitted Mar 04, 2020. Accepted for publication Mar 18, 2020.

doi: 10.21037/hbsn.2020.04.07

View this article at: http://dx.doi.org/10.21037/hbsn.2020.04.07

\section{Introduction}

Liver surgery for colorectal liver metastasis (CRLM) has evolved considerably over the past two decades. Novel chemotherapy regimens and effective targeted therapy, changes in the view of resectability criteria and evolution of safer surgical principles have led to increasing resection rates and better overall survival for an increasing number of patients with stage IV colorectal cancer (1).

While the survival benefit from resection CRLM is welldocumented and long reported in the medical literature, there continues to be a disturbing variation in the access and provision of liver surgery across population-based studies. Indeed, variation in the delivery of surgical services is welldescribed in general, but many aspects of its causes a poorly understood. Variation in the provision and outcomes of liver surgery has been demonstrated in several nationwide studies from Germany (2), Sweden (3), and Norway (4). A UK-based study in the early 2000s (5), demonstrated a low resection rate for CRLM. In the period from 1998 to 2004, the hepatectomy rate in the UK increased from $1.7 \%$ to $3.8 \%$, suggesting an underutilization of liver surgery as such in the population. A $<4 \%$ resection rate was arguably well below the $>10 \%$ reported from the MD Anderson during the same period (1) and far below that rate levelling off at about $20 \%$. Notably, the increase in resection rate came with the introduction of novel and more effective chemotherapy regimens, pointing to the importance of multidisciplinary evaluation and management to optimize treatment strategy for improved outcomes.
Obviously, resection rates in a single-institution referral centre cannot be used as reference for a populationbased study. However, in a population-based study from Norway, a resection rate at around $20 \%$ was demonstrated with negligible variation between regions (4). Thus, when revisiting UK data in the largest population-based study to date (6), it is concerning to see the resection rate reported at $4.1 \%$ in 2005 only increase to and plateauing at around 5\% in 2012. The very slow take-up on liver surgery $(5,6)$ and potential 4-fold lower resection rate in UK (about 5\%) (6), compared to institutional and contemporary populationbased rates $(1,4)$ (about $20 \%$ ) is concerning. Causes to this variation needs to be explored.

\section{Causes to variation in resection rates for CRLM}

In principle, resection rates are influenced by a core set of variables: first, the patients must be deemed fit enough to receive medical care and surgery; second, the patient must be evaluated for the CRLM by a team that have the available tools and knowledge to provide optimal care; and, lastly, the health care system must be set up to allow for appropriate detection, referral, evaluation and treatment for the condition.

\section{Health systems barriers to CRLM resection?}

Variation in selection to surgery is already reported for primary colorectal cancer, as demonstrated in population- 
based data across UK and Scandinavian countries (7). In a comparative, nationwide cohort study, there was a notable 3 -year survival difference between stage IV cancers in UK (stage IV colon cancer 20.5\% 3-year survival, 95\% confidence intervals 19.9-21.1\%) compared to Norway (stage IV colon cancer $33.0 \%$, 95\% confidence intervals $31.0-35.1 \%)$ (7). The resection rate for primary cancers was also considerably lower in the UK, and most of the difference was found in patients $>75$ years of age. The age gradient of the decline in the proportion of patients treated with resectional surgery was steeper in England across all stages compared to all other countries (Norway, Sweden and Denmark) (7). In a nationwide cohort from Norway (8), a total of $16.3 \%$ of all liver surgery was done in patients $>75$ years of age.

The differences may point to important variations in cancer care pathways that influence decisions to operate and, hence, outcomes. Of note, less than $3 \%$ of all patients had a "liver-first" resection in the cohort (6), suggesting that priorities are heavily skewed towards resection of the primary. Variation in diagnostic pathways and delays may be one explanation for the observed differences, as recently demonstrated in a large study across the same countries (9). The variation in diagnostic pathways and referrals seem to apply to primary as well as metastatic disease. Hence, general or colorectal surgeons may not be the barrier to referral [as suggested in the discussion (6)], but rather other factors may be at hand that impede on appropriate and timely treatment.

\section{Knowledge barriers to use of hepatic resection in CRLM}

Indeed, variation in referral patterns for CRLM is readily described in the UK (10), and also reflected in the recent paper (6). Receiving a liver resection was more likely if the primary tumour was operated in a centre with a liver surgery service present. Consequently, patients evaluated at MDTs with no liver surgeon may have been deemed irresectable and not referred. In the UK, evaluation of all primary liver tumours in a MDT with a liver surgeon is mandatory, while discussion of secondary liver tumours in MDTs (with a liver surgeons) is not. This should be noted as an important difference in the variation, as such evaluation of all CRLMs is mandatory in the Nordic countries and, as such, avoids the dilution of decisions to surgeons, oncologists or gastroenterologists with little or no first-hand experience in the state-of-the-art liver surgery. Indeed, the effect of having the presence of a specialist liver surgeon on evaluation of resectability for CRLM is welldocumented $(11,12)$, as is the noted discrepancies between specialists in evaluating appropriateness of surgery for liver metastasis (13). Commonly perceived contraindications to liver resection include extrahepatic disease, poor performance status, the presence of $>4$ metastases, bilobar metastases, and larger size (e.g., $>5 \mathrm{~cm}$ ) of metastasis (14). Many of these may be relative indications-even the elderly with a relatively poor performance status can be offered liver surgery if liver limited disease is located in a favourable location with low risk. Increasingly, liver surgery can be delivered by minimal invasive access and with low complication burden in most instances-hence age and comorbidity may be relative rather than absolute contraindications. Notably, in the parenchyma-sparing era of liver surgery moving away from formal resections as a default, the vast majority of liver resections are now classified as 'minor' and one-third of these (with rates increasing) can be done by laparoscopic access (8).

\section{Age- and gender-biased selection?}

This study has confirmed the findings of a number of previous large retrospective analyses that after controlling for confounders including Charlson co-morbidity index, access to liver resection is inequitable amongst women, older people and patients from deprived socioeconomic backgrounds (6). Colorectal cancer is a disease known to be strongly influenced by gender, with a significantly higher incidence and overall mortality rate observed in men (15). These differences however equalise at advanced stage, with a similar proportion of women as men diagnosed with stage III and IV disease. Although women made up $44.2 \%$ of the cohort in the UK study (6), only $37.2 \%$ of those undergoing liver resection were women. Multilevel regression analyses revealed that after controlling for co-morbidity and stage, women had an adjusted odds ratio of liver resection of 0.77 (95\% CI, 0.73-0.81). The reasons behind this are likely to be complex but need to be further explored. National registries and population-based cancer statistics should have sufficient resolution to identify true significant health inequalities between population groups.

\section{Minimal hospital volume or population-based resections?}

One reason cited as an explanation for the under-referral to specialist MDTs is a lack of awareness of multimodal 
treatment options for patients with bilobar disease, including multistage hepatectomy. The drive towards centralisation of HPB services has assumed that the survival benefits conferred by concentrating delivery of care to high-volume units outweigh potential downfalls including inequity of access to services, but data on the magnitude of these effects are lacking. Regulation of minimum surgical case numbers has been the principal stimulus to centralisation. One solution might be to routinely monitor resection rates and patient outcomes on a population level rather than institutional case volumes.

\section{Conclusions}

It is imperative that barriers to surgery for patients with colorectal liver metastases are addressed as it is known that reversing underutilization of resection improves survival. Involvement of a hepatobiliary surgeon in 'spoke' colorectal MDTs might reduce but will not eliminate variability. One way forward may be introduction of mandatory evaluation and discussion of all CRLMs in MDTs by a (at least one or more) proficient liver surgeon to avoid underutilization of optimal strategies for CRLM management. A renewed look at current patient pathways may be needed across and within existing health trusts to ensure optimal referral patterns and utilization of resources. Increased awareness and education of community doctors may be warranted to avoid a nihilistic attitude to liver surgery. Further, health providers should consider liver resection rates per population rather than individual institutional volume when assessing indicators of service quality. Notably, current evidence does not allow for consensus as to what threshold at which the minimum resection rate should be set. However, the current resection rates in England as reported (6) is far below the rates reported by others $(1,4)$, and is in need of reorganization to avoid depriving patients for a documented survival benefit.

\section{Acknowledgments}

Funding: None.

\section{Footnote}

Provenance and Peer Review: This article was commissioned by the editorial office, Hepatobiliary Surgery and Nutrition. The article did not undergo external peer review.

Conflicts of Interest: Both authors have completed the
ICMJE uniform disclosure form (available at http://dx.doi. org/10.21037/hbsn.2020.04.07). The authors have no conflicts of interest to declare.

Ethical Statement: The authors are accountable for all aspects of the work in ensuring that questions related to the accuracy or integrity of any part of the work are appropriately investigated and resolved.

Open Access Statement: This is an Open Access article distributed in accordance with the Creative Commons Attribution-NonCommercial-NoDerivs 4.0 International License (CC BY-NC-ND 4.0), which permits the noncommercial replication and distribution of the article with the strict proviso that no changes or edits are made and the original work is properly cited (including links to both the formal publication through the relevant DOI and the license). See: https://creativecommons.org/licenses/by-nc-nd/4.0/.

\section{References}

1. Kopetz S, Chang GJ, Overman MJ, et al. Improved survival in metastatic colorectal cancer is associated with adoption of hepatic resection and improved chemotherapy. J Clin Oncol 2009;27:3677-83.

2. Filmann N, Walter D, Schadde E, et al. Mortality after liver surgery in Germany. Br J Surg 2019;106:1523-9.

3. Gilg S, Sparrelid E, Isaksson B, et al. Mortality-related risk factors and long-term survival after 4460 liver resections in Sweden-a population-based study. Langenbecks Arch Surg 2017;402:105-13.

4. Angelsen JH, Horn A, Sorbye H, et al. Populationbased study on resection rates and survival in patients with colorectal liver metastasis in Norway. Br J Surg 2017;104:580-9.

5. Morris EJ, Forman D, Thomas JD, et al. Surgical management and outcomes of colorectal cancer liver metastases. Br J Surg 2010;97:1110-8.

6. Fenton HM, Taylor JC, Lodge JPA, et al. Variation in the Use of Resection for Colorectal Cancer Liver Metastases. Ann Surg 2019;270:892-8.

7. Benitez Majano S, Di Girolamo C, Rachet B, et al. Surgical treatment and survival from colorectal cancer in Denmark, England, Norway, and Sweden: a populationbased study. Lancet Oncol 2019;20:74-87.

8. Lassen K, Nymo LS, Olsen F, et al. Contemporary practice and short-term outcomes after liver resections in a complete national cohort. Langenbecks Arch Surg 
2019;404:11-9.

9. Weller D, Menon U, Zalounina Falborg A, et al.

Diagnostic routes and time intervals for patients with colorectal cancer in 10 international jurisdictions; findings from a cross-sectional study from the International Cancer Benchmarking Partnership (ICBP). BMJ Open 2018;8:e023870.

10. Young AL, Adair R, Culverwell A, et al. Variation in referral practice for patients with colorectal cancer liver metastases. Br J Surg 2013;100:1627-32.

11. Jones RP, Vauthey JN, Adam R, et al. Effect of specialist decision-making on treatment strategies for colorectal liver metastases. Br J Surg 2012;99:1263-9.

12. Choti MA, Thomas M, Wong SL, et al. Surgical Resection Preferences and Perceptions among Medical Oncologists
Treating Liver Metastases from Colorectal Cancer. Ann Surg Oncol 2016;23:375-81.

13. Homayounfar K, Bleckmann A, Helms HJ, et al. Discrepancies between medical oncologists and surgeons in assessment of resectability and indication for chemotherapy in patients with colorectal liver metastases. Br J Surg 2014;101:550-7.

14. Krell RW, Reames BN, Hendren S, et al. Surgical Referral for Colorectal Liver Metastases: A Population-Based Survey. Ann Surg Oncol 2015;22:2179-94.

15. White A, Ironmonger L, Steele RJC, et al. A review of sex-related differences in colorectal cancer incidence, screening uptake, routes to diagnosis, cancer stage and survival in the UK. BMC Cancer 2018;18:906.
Cite this article as: Guest RV, Søreide K. Addressing the variation in hepatic surgery for colorectal liver metastasis. HepatoBiliary Surg Nutr 2021;10(1):103-106. doi: 10.21037/ hbsn.2020.04.07 